\title{
A PSEUDOCIÊNCIA DO DESIGN INTELIGENTE
}

\section{THE PSEUDOSCIENCE OF INTELLIGENT DESIGN}

Rafael Nicolaidis ${ }^{1}$

Clin Biomed Res. 2016;36(1):56-57

1 Serviço de Emergência, Hospital de Clínicas de Porto Alegre (HCPA). Porto Alegre, RS, Brasil.

Autor correspondente:

Rafael Nicolaidis

rnicolaidis@hcpa.edu.br

Serviço de Emergência, Hospital de

Clínicas de Porto Alegre

Rua Ramiro Barcelos, 2350.

90035-903, Porto Alegre, RS, Brasil.
A Clinical \& Biomedical Research publicou uma carta muito interessante em sua última edição. O autor apresenta a teoria do "design inteligente" (DI), definindo-a como "uma teoria científica que defende que certas características do universo e dos seres vivos são mais bem explicadas por uma causa inteligente ao invés de processo não direcionado, como a seleção natural"1:250.

Mas seria mesmo o DI uma teoria científica? Uma teoria científica não é um mero palpite ou uma simples achismo: pressupõe uma ou mais hipóteses testadas empiricamente através de experimentos ${ }^{2-4}$. A seleção natural é uma teoria científica. O DI, por outro lado, não pode ser considerada uma teoria científica, já que não existe maneira de verificar experimentalmente sua afirmação central, a existência de um "Criador". Os proponentes do DI frequentemente utilizam a dualidade de significados da palavra "teoria" (coloquial versus científico) para afirmar erroneamente que o DI é uma teoria científica, ou ainda que a seleção natural é "apenas" uma teoria.

Alves afirmou que "cada vez mais adeptos têm-se unido à comunidade pró-design"1:250, citando como referência o documento "A Scientific Dissent from Darwinism"5, um abaixo-assinado que, em 2007, após 6 anos de existência, continha aproximadamente 700 assinaturas, entre elas as de cientistas falecidos e muitos pesquisadores de áreas sem relação com as ciências da vida. Em contraste, uma contrapetição intitulada "A Scientific Support for Darwinism" obteve, durante apenas quatro dias de 2005, assinaturas de 7.733 cientistas $^{6}$.

Os defensores da ideia do DI usam a falácia da "complexidade irredutível", argumentando que funções ou órgãos complexos, como um olho ou o flagelo de uma bactéria, não seriam explicáveis dentro do paradigma da seleção natural, por dependerem de múltiplos componentes (e consequentemente múltiplas mutações) que não poderiam ter surgido simultaneamente e que, individualmente, não confeririam vantagens adaptativas. Essa teoria já foi testada (conforme o método científico) e refutada através de modelos computacionais que demonstraram que o mecanismo de seleção do mais apto é capaz de gerar sistemas de alta complexidade ${ }^{7}$. A "complexidade irredutível" do olho já foi reduzida através de demonstrações fósseis de sua evolução ${ }^{8}$. Pesquisadores também propuseram caminhos evolucionários viáveis para sistemas considerados irredutíveis pelos criacionistas, como o flagelo de uma bactéria ${ }^{9}$.

Curiosamente, uma busca na base de dados MeSH da NCBI (National Center for Biotechnological Information) por "Intelligent Design" gera o seguinte resultado: o MeSH "Religious Philosophies"10.

Alves conclui a sua carta pedindo "uma mente aberta" aos corpos editoriais dos periódicos científicos, característica realmente desejável, mas que não deve servir para deixarmos de lado os princípios fundamentais da ciência.

$\mathrm{MeSH}$ terms:

- Epistemology, Epistemologia

- Intelligent Design, Design Inteligente

- Natural Selection, Seleção Natural

- Science, Ciência

- Science and Religion, Religião e Ciência 


\section{REFERÊNCIAS}

1. Alves EF. Teoria do design inteligente. Clin Biomed Res. 2015;35(4):250-1.

2. National Academy of Science. Terms used in describing the nature of science. In: Science and creationism: a view from the National Academy of Sciences [internet]. 2. ed. Washington: NAP; 2001. [cited 2016 Feb 13]. Disponível em: www.nap.edu/ read/6024/chapter/2\#2

3. Rasmus Grønfeldt Winther. The structure of scientific theories. In: Zalta EN. Stanford Encyclopedia of Philosophy [internet]. Stanford: The Stanford Encyclopedia of Philosophy; 2016. [cited 2016 Feb 13]. Disponível em: plato.stanford.edu/entries/ structure-scientific-theories/
4. American Association for the Advancement of Science. The nature of science [internet]. 1989. [cited 2016 Feb 13]. Disponível em: www. project2061.org/publications/sfaa/ online/chap1.htm\#sci

5. Discovery Institute. A scientific dissent from Darwinism [internet]. Seattle; 2001. [cited 2016 Feb 13]. Disponível em: www.dissentfromdarwin.org/

6. Wikipedia, the free encyclopedia. A scientific support for Darwinism [internet]. 2014. [cited 2016 Feb 13]. Disponível em: en.wikipedia. org/wiki/A_Scientific_Support_for_ Darwinism
7. Lenski RE, Ofria C, Pennock RT, Adami $\mathrm{C}$. The evolutionary origin of complex features. Nature. 2003;423(6936):139-44.

8. Young GC. Early evolution of the vertebrate eye: fossil evidence. Evol Educ Outreach. 2008:1(4):427-38.

9. Pallen MJ, Matzke NJ. From The Origin of Species to the origin of bacterial flagella. Nat Rev Microbiol. 2006;4(10):784-90.

10. National Center for Biotechnology Information. Religious philosophies [internet]. Bethesda: NCBI. [cited 2016 Feb 13]. Disponível em: http://www.ncbi.nlm.nih.gov/ mesh/?term=intelligent+design

Recebido: Fev 14, 2016 Aceito: Fev 24, 2016 